\title{
Care of the collection in University of Peradeniya library: strategic planning for the preventive conservation
}

\section{Author}

\section{Alahakoon, Champa N.K.}

MLS (Colombo)

Senior Assistant Librarian

University of Peradeniya, Sri Lanka

\section{Contact Details}

$\begin{array}{ll}\text { E-mail: } & \text { kumaria@pdn.ac.lk } \\ \text { Tell }: & 00-94-81-2392474 \\ \text { Fax: } & 00-94-81-2392470\end{array}$

\section{Abstract}

This paper discusses some problems which prevail with regard to preventive conservation of rare materials presently available in the university library. It reveals the problems that have arisen due to deteriorating factors and negligent areas of the library, such as lack of awareness of the importance of the documents and materials; lack of positive thinking on preventive conservation; shortage of trained staff, equipment and chemicals; and lack of funds. It points out the importance and 
need of preservation of different kinds of material including wooden objects and paintings and the factors that need to be addressed with regard to preventive conservation. Lastly it highlights strategic planning for preventive conservation which needs to be implemented.

Key words: Collection care, preservation of rare materials, strategic planning for preservation

\section{Preamble}

Among the university libraries, the University of Peradeniya Library has the greatest importance because of variety of rare and valuable documents. On the other hand the birth of this library was in the year 1942 , and now it has reached its $66^{\text {th }}$ years and is the oldest academic library in Sri Lanka.

The university of Peradeniya library has now reached an important stage in its development over the last sixty six years, and the materials of the collection are needed to be safeguarded and strengthened. No university can survive without its library. To be true university library, it should safeguard the heritage that it stores. The main objective of this library is to promote and provide information to undertake dynamic research as well as to support study and teaching from its wealth of materials. Thus, there is a need to retain and preserve for authentic surveys of posterity. According to the saying " $A$ true university is more than a soul-less degree factory" (Goonetileke, 1973) the librarians and others need to be well aware of the collections under their custody. 


\section{Rare materials in the Library}

University of Peradeniya library has wide range of collections of the country's written heritage and different types of cultural materials such as a large collection of ancient incised palm-leaf manuscripts, and some paper manuscripts written with ink. In addition to these records, there are printed books and periodicals, copper plates, some newspaper documents, paper paintings and drawings of scenes, photographs, and microfiche. Old masks collection, and wooden almirahs, chairs, and tables are also very valuable assets. In order to preserve the vast written records in the library, microfilming was also introduced and some of the selected rare collections in the library were microfilmed and the project was finished by 1992 .

\section{Nature and deterioration of library materials}

It is obvious that whatever the materials and what ever its constituents, they deteriorate over time, some slowly, others faster and yet others due to demand of usage. Before implementing preventive measures, knowledge of the nature of the materials and the impact of the various deterioration factors must be recognized (Agrawal, 2000). The most important constituents of paper fibers are cellulose and lignin. Lignin is more vulnerable to destructive agencies than cellulose and therefore it is more important from the preservation point of view. (Agrawal, 1993) With time, paper becomes brittle due to acidic and some times fungus and insect attacks.

Though the basic constituent of the palm leaf is cellulose, with the action of oxygen and ultra violet radiation, it loses flexibility and becomes 
brittle. In the absence of required oil layer of the manuscripts, the durability of the leaves cannot be estimated and insects, fungus, cracks, torn, cleavage of layear and dust attack them very easily.

Microforms are another resource available in this library. Microfilm copies or positives can be prepared by using the negative film only. High temperature and humidity accelerate the growth of microorganisms and spots on films are quite a common phenomenon in an uncontrolled environment.

Wooden furniture and objects, also being of organic material, are especially susceptible to deterioration and great care is required for their preservation. Almost all the materials of the library are wooden structures and wooden objects and therefore it needs utmost care and attention because of the nature of the wood which is fibrous and of cellular structure. Storage, safeguards, durability and transportation need to be considered when handling the objects in the library.

There are a large number of paintings in the library and most of them are donations. The danger exists of the growth of micro-organisms on paintings in humid surroundings. Light also is very damaging to paintings and leads to fading of colour.

\section{Strengths of the rare materials and objects Collections of books}

The University of Peradeniya has been enriched with several important rare collections, which were acquired through donations, bequests and purchases from private hands, and presently the following can be 
mentioned as the rare and important materials that need to be preserved. 2338 invaluable books related to Ceylon history and archaeology was donated by Leslie de Seram. Another important collection is, Sir Henry de Mel's collection which includes 327 books donated with two decorative Dutch almirahs. Presently the collection is stored with the W.A. de Silva collection and Donald Ferguson's collection donated by Mr. D.R. Wijewardena which includes 1289 and 176 books respectively, with 62 maps in Ferguson's collection of Ceylon and Asia. The biggest collection of books purchased by the library in 1968 was from Muhandiram D.P.E. Hettiarachchi, of 11,766 including some palm leaf manuscripts. Mr. Hettiarachchi's collection includes another two great Sri Lankan scholars writings namely, Ananda Coomaraswamy and James D'Alwis. The writings of Ananda Coomaraswamy include copies of articles gleaned from less known sources. Another is M.D. Ratnasuriya's collection which includes 220 books relating to Sinhala literature and Ceylon history. The Richard Abeysekara collection of 135 books and journals about archaeology are kept as reference materials in the library. Apart from these, there are about 650 books kept as reserve collection, which are in non-restorative condition but considered as rare and out of print materials. Two manuscripts written on velum have been presented by Dr. Paul E. Pieris. The materials such as Ceylon Blue Books and the Ceylon Almanac are also valuable materials in this collection.

\section{Palm leaf Manuscripts}

Apart from the rare books, the second largest collection of palm-leaf manuscripts of over 5000 on various subjects is housed in the library, including one of the oldest Palm leaves so far found in Sri Lanka namely Vissuddhi Magga Tika in the $13^{\text {th }}$ century. The tools and materials which 
were used for writing, preparation of leaves and clothes used for storage are also available.

\section{Paintings and drawings}

The library owns many drawing books and paintings of various periods in the history of the island, including voyages in 1841-1846 by Dans L'inde; drawing plates of "A Picturesque illustrations of the Scenery, Animals and Native inhabitants of the Island of Ceylon" 1808 by Samuel Daniell, the site maps of "Architectural remains of Anuradhapura Ceylon", illustrations of Sir. I.E. Tennent's work of "A series of fifteen views in Ceylon in 1864, Dutch records of Ceylon Government Archives (Tombo) and this includes School and Head and Land Tombos; a volume of four drawings and hand written manuscripts of Major and Mrs. G. Darby Griffiths' "Ceylon during a residence in the years 1841-1842". Ceylon Drawings (1846-1852) by Mrs. M. Branker is another important book in water colours, pencil, pen and ink which includes 90 drawings. The library owns a copy of the "Ceylon Drawings" by S. Daniell published in $\mathbf{1 8 0 8 .}$

There are about 300 paintings in the library and most were donation by the famous bibliographer of Ceylon and a one of the former librarians of university of Peradeniya,Mr. Ian Goonetileke (Goonetileke, H.A.I., 2004).

\section{Papers and maps}

The centenary number of the "Ceylon Observer-1834-1934" and the "Times of Ceylon-1846-1946" newspapers are in the library. In addition to these there are about 66 large scale maps of Asia and Sri Lanka, in the 
Ferguson collection. Additionally, there are about 30 maps of Sri Lanka with the present collection which are rolled and kept.

\section{Wooden objects and furniture}

The library has an invaluable collection of Masks (Kolam) which have been painted by using natural paint and these masks are used for "Maname Nadagama". There are about 55 masks displayed in the ground and the first floors of the library. There are also some valuable carved wooden Dutch Almirahs, carved and decorated door-frames, tables and chairs in the library, which are of archival value. Wood, although seemingly hard and durable, need care.

Even though the slow decomposition of library materials is a universal and uncontrolled problem, they should remain available to present and future generations of library users. For safeguarding of the rare materials, the library has microfilmed the 15 important collections (Senadeera, 1991) in 1982 including some of the donations and there are about 2035 master microfilm reels stored in the library.

The collections mentioned above are considered as rare and some are in a deteriorated condition due to many reasons. As these are permanent reference materials, the collections are in unchanged manner for a long time due to the factors such as climate, temperature and humidity which are not in a proper required order for the collections in this storage. Therefore it is needed to work out a proper standard for the safety storage and handling of the important and rare materials and it is an important factor which has to be taken into account in academic library as many can be used for researches. 


\section{Negligence factors}

Most of the materials mentioned above are in a decaying and deteriorating condition, and some are severely damaged due to physical and biological agents. Presently, though the library network has more than 700,000 volumes of materials the library lacks a fumigation chamber (fungicidal/ insecticidal) which can accommodate a certain amount of materials at a time. A small naphthalene chamber which is inadequate. At the same time, the material which needs periodical cleaning and care (palm leaf-blackening and oiling) is neglected due to other priorities in the library. As some of the collections are stored in the non-ventilated areas of the library due to lack of space, it is necessary to control the humidity and temperature to the required level to prolong the life span of these materials.

In rare and special collections, the collection care and technique of handling the materials are very much important. Though some rare collections have been microfilmed, care is needed for the originals, as microfilm preserves only the content of the material and so far no positive copies have been made or no duplicate films provided to another library for preservation. Though, there are advantages of microfilming, the following have to be changed within the microfilming project.

1. Less care given so far to the originals of the microfilmed materials.

2. No preventive conservation methods applied for originals.

3. As the originals are not been used, deterioration is caused. Fungus, insects etc. attack documents.

4. No high quality storage facilities for microfilms. 
5. Only negative films are preserved, the positive films or copies of the microfilms need to be prepared.

Presently the in-house binding unit is greatly help preservation of the collection. In binding more advanced techniques for preservation of materials have to be undertaken.

\section{Facts that need to be considered}

After a visual observation and survey, the following basic problems pertaining to the library with regard to preventive conservation of the library materials has emerged.

- Lack of awareness of the value and importance of rare library materials including books.

- Non-availability of adequate measures for preventive conservation.

- Lack of trained / knowledgeable staff for preservation and to safeguard materials.

- Careless of storage, display, selection of materials for bindings, repairs, mending and fumigation at the required moment.

- Lack of proper cleaning schedule, preventive measures and careless handling of all types of rare and valuable collections including paintings, masks, palm-leaves and etc.

- Lack of awareness of causes of deterioration such as physical, chemical, biological, improper storage, risky handling, internal causes and poor quality of the materials.

- Time-consuming administrative procedures of the purchasing or rehabilitation of preventive requirements in the university systems. 
As described earlier, it is obvious that there is a need to work out a strategy for the preservation of different kinds of materials in the library. There are different techniques of reformatting available such as photocopying, digital imaging, and microfilming. Photocopying is the most common and useful production of a single copy of a manuscript or book but the copies may be less permanent than the original paper document.

Except the documentary heritage of the library, others need to be considered for safeguarding of the materials. The wooden furniture and other materials like masks, paintings, photos etc. The cleaning, application of preventive care and the handling of the materials, their repair, maintenance, and improvement of durability within a consideration of environmental factors need to be examined. This is essentially technical, and specialized treatment is necessary for various kinds of materials. Due to its nature, the separate chemical treatment in respect of particular damage or deterioration will be required (Pandey, 1990). According to the nature of the paintings some are not to be unstructured and unframed and should never be rolled. The frames add their beauty and protect them from damage.

\section{Strategic planning for preservation}

Preservation does not simply happen on its own. A well thought out plan must be drawn and managed. According to the fifth Law of Library Science "Library is a growing organism", libraries acquire materials of all kinds continuously, and promote the use of these acquired materials. With increased number of users they are more likely to be damaged. To prevent this deterioration of all kinds of materials which may affect the 
further retrieval of the contents, it is necessary to adopt an array of appropriate management strategies. For each variety of material there must be a separate, clear strategic plan for preservation. A major value of strategic planning can help the library to avoid the pro-active and reactive failings which can have a critical impact on preservation. The following cycle leads to stress and poor decision making of the preventive measures inside the library

Figure 1: The cycle of Preventive Measures

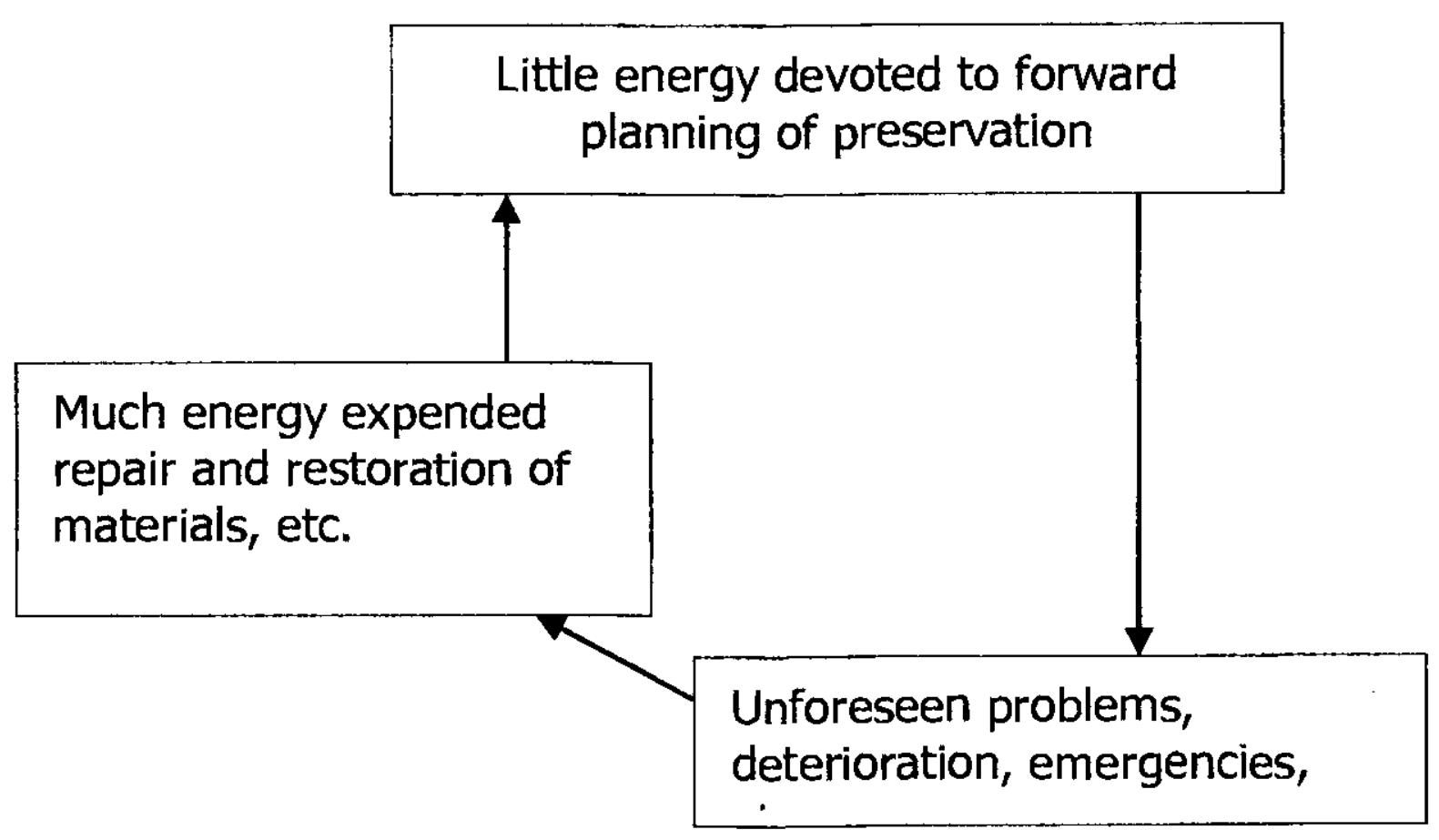

The purpose of the preservation should be

- To increase access to the collections through preventive conservation.

- To promote awareness of preservation issues within the library. 
What is needed to be considered with the strategic planning of preventive conservation of the library will help to address the above issues.

\section{Training of personnel}

In this kind of academic library it is very necessary to know about the preventive conservation methods of the custodians of the collections. The only positive insurance against their decay and damage is an organized preventive conservation programme, which should include training with adequate equipment and with practical instructions to those trained. The following areas of preservation need to be considered:

- Materials and their constituents and manufacturing technology with safekeeping and handling the materials.

- Training on identification of deteriorating factors: physical, chemical and biological.

- Knowledge and training of handling sophisticated machinery, equipment and tools.

- Practical training on fungicidal and insecticidal treatment and fumigation.

- Establishment of safe storage facilities for microfilms and other important materials according to established standards.

- Type of storage, shelving, handling and maintenance of the collection and building.

- Transportation technique of the materials, when moving of material is necessary.

- Short term workshops, seminars, lectures, or handouts about preventive conservation techniques. 
- Purpose of cleaning and correct method of cleaning.

- Safety precautions and first-aid treatment for those engaged in preservation activities using chemicals etc.

- Maintenance of constant temperature $\left(22-23^{\circ} \mathrm{C}\right)$ and relative humidity (45-50\%).

- Positive attitude regarding importance of preservation of library materials.

- Workable policy documents for the whole function of the library procedures including preservation policy.

- Knowledge of application of correct methods of storage for each different kind of material and the care of the materials.

\section{User awareness programmes}

The first step of the user awareness programme is to emphasise the authenticity of the materials as primary sources available in the country and their protection. The following will address the issue (Alahakoon, 2003).

- Provision of rules and regulations about the handling of materials.

- Responsibility should be placed on the reader to look after the item used.

- Encourage the use of microfilmed copy.

- A fine to be levied, if an item is damaged by a user.

- Orientation tour for the users of the library.

- Exhibitions with regard to misused library materials to make clear damage caused to valuable/ rare materials. Broachers would be useful. 


\section{Conclusion}

Preventive conservation is both time consuming and expensive, and it will almost certainly be necessary to set priorities for the treatment of specific items in the collection. Factors considered are the rarity, significance, and value of the materials and the demand for its use, its present status, archival value and the existence of, or need to create, a surrogate. It is imperative that important preventive conservation programmes are implemented within the library. It is the duty of the librarian to preserve and conserve the intellectual content of the documents for the generations to come irrespective of media and technological changes. Earning of enough funds for preservation is the main problem to the library with the automation of the library holdings and though, very difficult, the physical environment should be improved to halt deterioration of rare materials in the library. The safest way to retain authentic testimony is to preserve the original. However, when the originals deteriorate for various reasons new ways must be looked into. Originals can be digitized in image form and electronically stored and processed. Digital imaging is not suitable for permanent storage. The main advantage lies in the fact that digitization increases accessibility, functionality and output capability to other media (Wettasinghe, 2004). The decision can be based according to the following table (MenneHaritz, A. Brubach, N. 2001).

\begin{tabular}{|c|c|c|}
\hline Use Method & Convertible & not convertible \\
\hline $\begin{array}{l}\text { 1. Imaging with } \\
\text { particular procedures }\end{array}$ & \begin{tabular}{lr} 
- & \multicolumn{3}{l}{ deliberately } \\
used colours \\
(such as \\
coloured pens \\
coloured print
\end{tabular} & $\begin{array}{l}\text { - } \quad \text { unusual } \\
\text { - } \quad \text { appearance } \\
\text { - } \quad \text { market value } \\
\text { - } \quad \text { display value } \\
\end{array}$ \\
\hline
\end{tabular}




\begin{tabular}{|c|c|c|}
\hline & $\begin{array}{lr}\text { in literature); } \\
\text { chance } & \text { colours } \\
\text { and r signs } \\
\text { difficult re to } \\
\text { recognise (e.g. } \\
\text { ink ryy, } \\
\text { watermarks) }\end{array}$ & $\begin{array}{l}\text { binding method } \\
\text { and form }\end{array}$ \\
\hline $\begin{array}{l}\text { Imaging with } \\
\text { standard microfilm } \\
\text { and microfiches }\end{array}$ & $\begin{array}{l}\text { note form } \\
\text { - } \\
\text { order of pages } \\
\text { of sides } \\
\text { particular } \\
\text { design } \\
\text { texts and their } \\
\text { arrangement } \\
\text { (organization, } \\
\text { placing of } \\
\text { illustrations) } \\
\end{array}$ & $\begin{array}{l}\text { as above for } 1 \\
\text { signs difficult to } \\
\text { recognize } \\
\text { (embossed } \\
\text { reliefs, faded } \\
\text { stamps) }\end{array}$ \\
\hline 3. extra textual & $\begin{array}{l}\text { the content of } \\
\text { texts (the } \\
\text { actual } \\
\text { information of } \\
\text { the writing in } \\
\text { files or books } \\
\text { for the resp. } \\
\text { addresses }\end{array}$ & $\begin{array}{l}\text { - } \text { as above for } 1 \\
\text { and } 2 \\
\text { - graphic order } \\
\text { connection to } \\
\text { illustrations }\end{array}$ \\
\hline
\end{tabular}

The decision to preserve originals or to convert them to other format must take into account the kind of features which influence the convertibility of the testimonial characteristic to be preserved.

\section{References:}

Agrawal, O.P. (1993). Preservation of art objects and library materials. India. National book trust.

Agrawal, O.P. (2000). Strategic planning for the preservation of manuscripts, books and documents. Asia Library News, Vol.3 No.1 
Alahakoon, C.N.K. (2003). Management, conservation and preservation of palm-leaf manuscripts: a research study based on selected collections in Sri Lanka. Unpublished M.L.S. thesis. University of Colombo.

Goonetileke, H.A.I. (1973). The library of the University of Ceylon, Peradeniya. Memorandum to the Royal Commission of Inquiry on the University of Ceylon, Peradeniya.

Goonetileke, H.A.I. (2004) Catalogue of paintings, drawings, water colours, etc., by Sri Lankan artists in the Ian and Roslin Goonetileke collection. Unpublished catalogue.

Menne-Haritz, A. Brubach, N. (2001). The Intrinsic Value of Archive and Library Material.

Available at:

http://www.uni- marburg.de/archivschule/intrinsengl.html\#intr06 Pandey, R.R. (1990). Problems and prospects of conservation of manuscripts in libraries. Conservation of manuscripts and documents: Problems and prospects. Lucknow. Indian Conservation Institute.

Senadeera, N.T.S.A. (1991). Microfilming for the safety of library materials. Information Development, Vol.7No. 4.

Wettasinghe, S. (2004). Digitization of Land records for access and preservation. Public Requirements and National Archives, Archives Week -Souvenir. 